\title{
Blockchain-based traceability in the food industry: requirements analysis along the food supply chain
}

\author{
Martina Thume ${ }^{a, d}$, Julia Lange ${ }^{b}$, Martin Unkel $^{c}$, Alexander Prange $^{a, d}$, Maik Schürmeyer ${ }^{a}$ \\ a Hochschule Niederrhein University of Applied Sciences, Faculty of Food and Nutritional Sciences, 41065 \\ Mönchengladbach, Germany \\ ${ }^{\mathrm{b}}$ FZI Research Center for Information Technology, Information Process Engineering Department, 76131 \\ Karlsruhe, Germany \\ c Fraunhofer-Institute for Applied Information Technology, Cooperation Systems Department, 53757 Sankt \\ Augustin, Germany \\ d University of Witten/Herdecke, Institute for Virology and Microbiology, 58448 Witten, Germany
}

\begin{abstract}
Traceability has become an important aspect in supply chain management, particularly in safetysensitive industries like food or pharmaceuticals. At the same time, blockchain arose as an innovative technology that has created excitement about its potential applications. Aim of this research paper is to analyze the requirements of the main stakeholders along the supply chain regarding a blockchainbased traceability system (BBTS). The supply chain is considered from agriculture to retail. The main result of this work is a specification framework, which consist of a supply chain process model describing activities relevant for food traceability, a collection of usage requirements formulated as data classes, a summary of technical requirements regarding data access, storage and processing, and interoperability requirements necessary to assure digital communication and permanent operability of the BBTS. Based on this, general application guidelines for digital information systems are derived and the blockchain technology is evaluated with regard to its potential in meeting requirements and challenges. A distinction between public and sensitive data appears to be necessary to assure traceability and trust in the supply chain. A two-part architecture involving a public permissioned blockchain network is proposed as the most promising basis for a digital traceability system in the food industry.
\end{abstract}

\section{Keywords}

Food supply chain, Traceability, Information system, Blockchain technology, Requirements

Contact:

martina.thume@hs-niederrhein.de, (ID) 0000-0002-5579-1466 (Martina Thume);

lange@fzi.de, (D) 0000-0001-8317-5751 (Julia Lange);

martin.unkel@fit.fraunhofer.de (Martin Unkel);

alexander.prange@hs-niederrhein.de (Alexander Prange);

maik.schuermeyer@hs-niederrhein.de, (ID) 0000-0003-3145-7401 (Maik Schürmeyer) 


\section{Introduction}

Supply chains in the food industry often extend beyond national borders and are globally spread. Across all branches, products and their relevant information are passed on vertically, i.e. along the respective supply chain, and horizontally, i.e. within the same supply chain stage. The requirements set out in this research paper are generally applicable to global supply chains, even if the analysis of legal requirements is limited to EU countries.

Since 2005, the EU regulation EC 178/2002 requires all food companies to provide evidence of the forward (track, "one step forwards") and backward (trace, "one step backwards") flows of goods to ensure the traceability of their products. This aims to secure food safety from primary production up to the delivery to the consumer. At the same time, the demand for transparency in food production, such as information on the origin of the raw materials used, but also more detailed information on the social or ecological sustainability of the goods, such as cold chain information or statements on the $\mathrm{CO}_{2}$ balance, have become increasingly important for consumers in recent years. (Lechner and Stocker 2020; Waskow and Burdick 2020; Pérez Ferreira Chaves and Peter 2018; Zhang et al. 2020)

This higher level of proof has placed further pressure on companies and resulted in supply chains becoming more complex. Therefore, new technologies are needed for the information management of food supply chains. (Croxson et al. 2019; Zhang et al. 2020)

However, integrated software systems are rarely used to share information throughout the supply chain today. Due to this, companies are hardly able to sufficiently meet traceability requirements that go beyond the legal regulations. Transparency of detailed product and process information in real time, as demanded by politics and society, cannot be completely achieved yet due to the following technical and economic causes:

- Technical: Heterogeneous IT infrastructures and digitization statuses of the integrated supply chain partners

- Economic: Internationally different hygiene standards, inconsistently used IT standards (e.g. GS1), lack of trust among supply chain partners and in central institutions for data management

Although the data collected since the introduction of EC 178/2002 allows statements on the origin of raw materials, it cannot provide more detailed information, e.g. monitoring of cold chains as required by the food hygiene regulation EC 852/2004.

To address the preventing issues and to meet the requirements for detailed information, a new approach is proposed: The blockchain technology, known since 2008, enables the construction of a decentralized, auditable and forgery-proof digital network. In this network, all involved actors can share process information in terms of transactions, chronologically and unalterably. Initial practical implementations (Food Trust Chain, Nutrisafe, BeefLedger, etc.) show that this technology can be used to provide reliable information fast. (Lechner and Stocker 2020; Hackett 2017; Cao et al. 2020) However, a well-founded requirements elicitation using a bottom-up approach that takes all relevant stakeholders along food supply chains into account is still missing. This may keep food producing companies from participating in information sharing and transfer, and traceability remains limited to the current extent. 
Within the scope of a project called SiLKe - Safe Food Chain, funded by the German Federal Ministry of Education and Research, a consortium of research institutions and industrial partners is investigating whether and how safety and transparency of food supply chains can be increased by using blockchain technology. (Reschke 2019) The aims of the project are, first, to deeply understand requirements and challenges of applying the blockchain technology in food supply chains and, second, to illustrate with an initial implementation of a digital platform how blockchain technology can ensure fast and secure traceability and protect information along supply chains against falsification. (Figure 1)

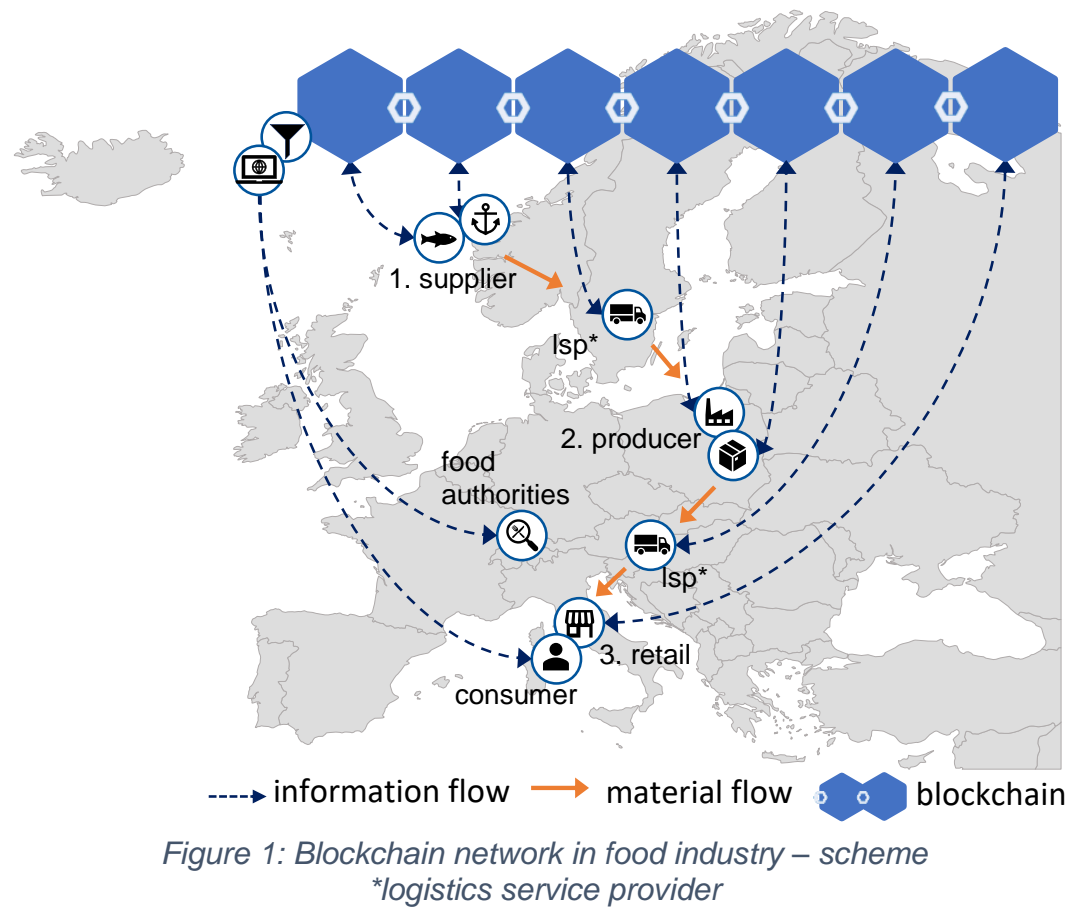

For this research paper the following research question has been derived from the overall objective: "Can a blockchain-based software system satisfy the requirements imposed on a traceability system in food supply chains?"

This work reports on the comprehensive determination and analysis of companies' needs and expectations, special interests of governmental institutions as well as functional and non-functional requirements as the important first step. Requirements and challenges are combined into a specification framework. More precisely, it is composed of a supply chain process model (SCPM), a structured collection of usage requirements and summaries of technical and interoperability requirements. Based on this, common conceptual guidelines for an open blockchain-based traceability system (BBTS) are derived.

This paper is organized subsequently as follows: Chapter 2 summarizes the current state of the art with regard to general processes and the blockchain technology in the food industry. Chapter 3 provides an overview of related literature and research projects. Chapter 4 describes the applied methodology, while Chapter 5 presents the specification framework as the result of the analysis. In Chapter 6 , challenges of the blockchain technology are discussed and the proposed research question is answered. Chapter 7 concludes with the main findings of this work. 


\section{Theoretical background}

\subsection{Processes in the food industry}

The following section describes models of internal and external processes along food supply chains. These descriptions form the basis for the development of the logistical process model in the later course of the research paper.

According to DIN EN ISO 9000 (2015), a process is defined as "Activity or [...] set of activities that uses resources to transform inputs into results". In literature, there are different definitions of processes. The common meaning is usually the description of the relationship between the following three elements: input, activities and output. (Clausen 2010, p. 12)

In the food industry, there exists a multitude of processes. However, the processes that take place along the supply chain can be divided into the categories of production structure (Dyckhoff and Spengler 2010, p. 170) (Figure 2):

- In smooth or continuous production (a), a product is created exclusively by processing the raw material (e.g., baking process of dough to become bread).

- In analytical or divergent production (b), several products are made from a single material (e.g., cutting a pig into its various parts).

- In synthetic or convergent production (c), several raw materials are combined into one product (e.g., production of juice from different fruits).

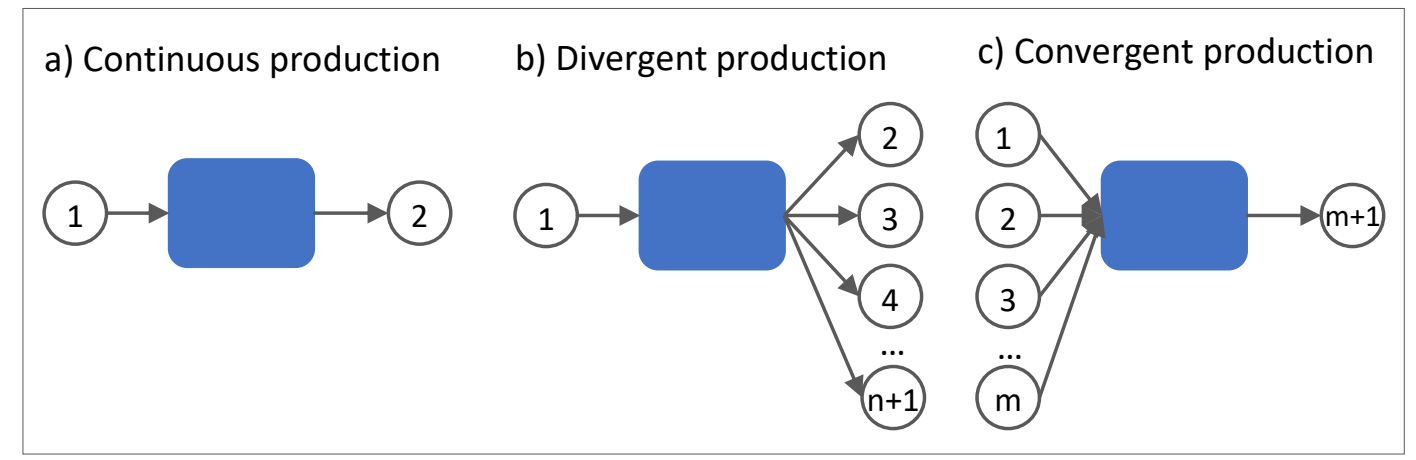

Figure 2: Categories of production structure according to Dyckhoff and Spengler 2010, p. 171

Food production and its upstream and downstream stages of the supply chain can vary greatly depending on the food produced and the degree of processing. Figure 3 shows a schematic representation of the structure of value creation stages in food production. Usually, a supply chain includes the extraction of raw materials and operating supplies, the primary production of plant or animal products as well as food production, wholesaling, retailing, hospitality industry and consumption of the manufactured products. It should be noted that not all stages always exist (e.g. direct purchase from the farmer). (Sommer 2007, $126 \mathrm{ff}$.)

The low level of branching is characteristic to value-added systems in the food industry. In addition to the supply chain shown in Figure 3, DIN 30781-1 focuses on logistical processes in the form of transport chains. According to this standard, the essential links within transport chains are

1. processes in which people or goods are moved from a source to a destination,

2. connections between physical resources and organizational areas (technical and organizational links)

3. and between the neighboring systems with which the transport chain is related. 


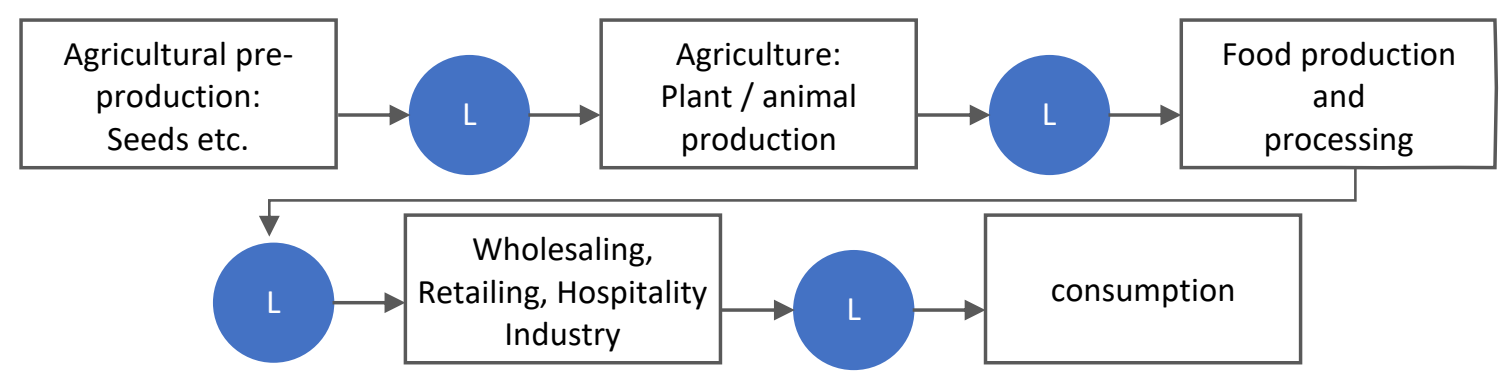

Figure 3: Structure of food supply chain according to Sommer 2007, p. 127; Casino et al. 2020, L: Logistical processes

While the technical linkage within transport chains presupposes the system's compatibility with the equipment used, the organizational linkage involves the coordination of the information and control systems. In this context, the neighboring systems are the production of goods (initial area, e.g. production) and the use of goods (final area, e.g. retailing). The challenge in describing logistics requirements therefore lies in the storage, handling and transport as well as the packaging and labeling processes. (Hackius and Petersen 2017)

In addition to the production and logistics processes, the processes for maintaining hygiene and food quality play another important role in traceability. On the one hand, they must be considered in the design of a BBTS to meet the demands of consumers. On the other hand, quality management, including quality assurance, is considered a key factor in ensuring food safety, transparency, associated traceability and liability as well as in restoring consumer confidence in food. (Casino et al. 2020)

\subsection{Blockchain technology in the food industry}

The term blockchain stands for an innovative technology (Nakamoto 2008), which enables the creation of a distributed electronic ledger. The ledger consists of linked blocks, where each block describes an information state upon which the majority of all network participants agreed. A block contains a list of cryptographically signed transactions which led to the state change from the previous to the current block. Cryptographic signatures and hashes are used to ensure the authenticity of each transaction and the integrity of all blocks. In summary, information in terms of transactions can be stored chronologically, irrevocably and unalterably in a digital network. Further information about the basic concepts of blockchain can for instance be found in Zheng et al. 2018.

Each participant can access a complete copy of all entries in the ledger at any time. (Morabito 2017; Nakamoto 2008) Data loss is also very unlikely, as this would require all partners to have a data loss at the same time. The involved Peer-to-Peer-technology allows the participants of a blockchain to interact in real-time. Since the information is stored in a distributed manner, there is no interface (cloud or similar) that may become a single point of failure and bring the system to a standstill. (Kamilaris et al. 2019; Schütte et al. 2017)

A system consisting of chronologically ordered, verified transactions forms the basis for the automation of inter-peer business processes. In the blockchain ecosystem, actors can bindingly agree on common business processes described by code snippets, whereby these agreements are often referred to as smart contracts or chain codes. These code fragments can only process verified information from within the ledger. They can be used to formally describe and automatically monitor 
rules and regulations, payment clarification and delivery conditions for goods or services. (Schütte et al. 2017; Morabito 2017)

Although blockchain technology is characterized by a high degree of transparency, it offers cryptographic methods for asymmetrical encryption to limit the visibility of information. The deletion of information can be formalized as a transaction, so that the information is removed in the following block state. Nonetheless, the history of transactions is not deleted, so the information can still be recovered.

A blockchain can be configured as public or private in terms of transparency and accessibility. In addition, the permissions of participants to co-determine the content and the processes of the blockchain can be defined as permission free or permissioned. (Welzel 2017, p. 14; Morabito 2017) An overview of possible combinations of both dimensions can be found in Table 1.

Table 1: Transparency and permission matrix

\begin{tabular}{|c|c|c|c|c|c|c|c|c|}
\hline Action & Public & \multicolumn{6}{|c|}{ Permissioned } & Private \\
\hline Sealing a new block & everyone & custom & & & & & & owner \\
\hline $\begin{array}{l}\text { Voting on transaction } \\
\text { acceptance }\end{array}$ & everyone & & custom & & & & & owner \\
\hline $\begin{array}{l}\text { Administrating chain } \\
\text { code }\end{array}$ & everyone & & & custom & & & & owner \\
\hline Executing chain code & everyone & & & & custom & & & owner \\
\hline Submitting transactions & everyone & & & & & custom & & owner \\
\hline Reading the ledger & everyone & & & & & & custom & owner \\
\hline $\begin{array}{l}\text { Accessing information } \\
\text { via a third-party API }\end{array}$ & everyone & & & & & & & custom \\
\hline
\end{tabular}

While in public blockchains everyone can participate, read, use existing services and offer new services, there are strict rules in a private blockchain. (Welzel 2017) Permissioned blockchains represent a hybrid form of public and private blockchains, in which permissions are regulated by a consortium. Such a consortium defines its organizational structure through contractually regulated governance. The goal of the consortium is to operate the blockchain for a common business purpose. The governance rules determine which permissions are exclusive to consortium members and which permissions are common to all. The permissions in Table 1 are sorted according to their impact on the proper fulfillment of the business purpose. Sealing a new block entitles that the participant may determine which of the valid transactions will be included in the next shared information state (block). Voting power on transaction acceptance means that participants determine which information is accepted or rejected. Anyone who can create and change chain codes controls the available business processes on the blockchain. These permissions have a strong impact on the credibility and business purpose of the network and can accordingly be restricted to members and controlled through governance rules. A further opening of these permissions enables participants to add their own business purposes to the network and thus develop an economy. The execution of chain code as well as the submission of transactions offer participants the possibility to go through the given business processes appropriately. With a public permission to read the ledger, non-members do not have to 
trust third-party services for the authenticity of information but can connect natively to the technology and audit the information at any time.

The blockchain configuration regarding transparency and permissions affects the consensus process. Public blockchains use consensus protocols that combine cryptographic puzzle systems with incentive mechanisms, such as Bitcoin's Nakamoto Protocol (Nakamoto 2008). Since an operator consortium can support trust through legal contracts, energy-saving consensus procedures can be used in the other cases. A Byzantine Faulty-Tolerant (BFT) consensus protocol, such as Practical BFT (PBFT) (Castro and Liskov 2002), is suitable for a permissioned blockchain. In private blockchain configurations even plain crash fault-tolerant (CFT) protocols, such as RAFT (Ongaro and Ousterhout 2014), can be considered. Since initial studies indicate that neither a public nor a private blockchain may be suitable to meet the needs of all stakeholders in food supply chains, the configuration of a public permissioned system will be considered in more detail in this paper. (Wüst and Gervais 2018)

In relation to Table 1, public permissioned refers to a blockchain configuration in which everyone can read the ledger, but the other permissions are reserved for consortium members. With the development of a comprehensive specification framework, a knowledgeable evaluation of the applicability of this configuration in a BBTS will be performed.

\section{Related work}

As described above, there is a growing interest in using innovative IT systems in food industry and logistics to make decisions based on more transparent information along supply chains. A standard application is the improved traceability of foodstuffs. This research paper mainly focuses on food traceability, software (especially information management) systems in supply chains and the use of blockchain technology in food supply. In the literature and mostly industry-driven research projects, two of these aspects are often considered, but there are only a few works dealing with all three.

Badia-Mehlis et al. (2015) present a study which gives an insight into new technologies (e.g. RFID or NFC) for full traceability. However, it also shows the difficulties and various problems in current food traceability (communication problems, inability to link food chain records). In this paper, requirements are formulated for these problems to be considered already in the development of the BBTS. Bhatt et al. (2013) discuss the question of how the growing demands for traceability in agriculture and food can be met. The authors develop a conceptual framework of basic principles and a desired approach to traceability without considering cost. The approaches presented add technology and standardization to existing practices. Both works highlight current challenges in food traceability, while the blockchain technology is not particularly addressed as a potential enabler, and specific requirements and challenges are not explicitly derived.

Mirabelli et al. (2020) present a summary of existing literature on the application of blockchain in the agricultural supply chain. Considering a large number of scientific papers, the authors summarize that the interest in applying innovative technologies is growing steadily. Nonetheless, only few case studies on blockchain solutions in agricultural supply chains exist so that there are still open research questions in this field. Vadgama and Tasca (2020) give an overview of the characteristics and application areas of 271 blockchain projects between 2010 and 2020. The authors conclude that the greatest portion of the projects can be assigned to the food and logistics sector, which indicates a commonly expected 
benefit from the usage of this technology in these areas. A detailed look at blockchain projects in the food sector is provided by the work of Kamilaris et al. 2019. The authors explain that currently, the potential of blockchain cannot be fully exploited due to barriers which involve technical aspects, education, policies and regulatory frameworks.

On the one hand, the analysis of these research papers shows the increasing presence and importance of blockchain technology in the food (logistics) sector. On the other hand, it becomes clear that the barriers described have their origin in the lack of comprehensive requirements surveys. The intended stakeholder-based requirements survey in this paper addresses this gap.

Casino et al. (2020) develop and test the distributed and secure architecture for blockchain including smart contracts for a food traceability. A case study of a dairy company is presented to assess the feasibility. The study shows that despite existing hurdles, blockchain technology has great potential in supply chain management. In contrast to Casino et al. (2020), this paper examines the challenges of implementing a blockchain-based software system together with the requirements of all stakeholders involved beyond the pure functionality of the technology.

The previously presented works focus on traceability and the use of blockchain technology in food supply chains. The previous articles do not focus on the development of software systems based on these topics. All three aspects, namely the traceability-focused implementation of the blockchain technology in food supply chains, are addressed in the following works.

The AgriBlockloT solution (Caro et al. 2018) is a fully decentralized, blockchain-based traceability solution for supply chain management in the agricultural industry. The authors present a technical comparison between two blockchain technologies regarding: latency, CPU load and network utilization. In contrast to the present paper, the results are technology-focused and are not based on a detailed requirements survey. In 2017, five global companies (Walmart, Unilever, Nestlé, Dole, IBM) have joined forces to investigate how blockchain technology can improve companies' food supply chains and contribute to data security. (Hackett 2017) The used blockchain is under the sovereignty of IBM, and thus, not actually decentralized. Moreover, the requirements for partners to participate are mainly raised by IBM and the industrial companies. A comprehensive analysis and discussion of these requirements is not reported.

Casado-Vera et al. (2018) follow the same conceptual idea as this present paper. In their work, they focus on building a new supply chain model adapted to blockchain technology. The model is piloted in the agricultural sector. Unlike in Casado-Vera et al., the supply chain model developed here is based on a detailed requirements analysis and can be applied to the entire food industry. Tian (2017) describes a BBTS for food chains. In contrast to the system considered here, the used blockchain has a central point for setting up and managing the blockchain - similar to IBMFoodTrust. In the following, a consortium solution is proposed and evaluated, which is supposed to provide a higher degree of transparency and authenticity for full auditability and trust. In addition, the author reports the use of a private permissioned blockchain, which significantly limits the range of requirements that can be raised (fewer stakeholders \& actions). For a public permissioned blockchain as considered here, a more extensive survey is necessary. Salah et al. (2019) show a blockchain-based solution and framework for traceability and visibility in the soybean supply chain using smart contracts. The authors discuss key aspects of their blockchain solution in terms of the overall system design and architecture and present, implement and test smart contract algorithms that govern and ensure the proper interactions among 
key stakeholders in the soybean supply chain. In contrast to the present paper, the underlying requirements elicitation is not explicitly addressed. Overall, the existing works give valuable insights regarding the applicability of the blockchain technology in food supply and highlight the need for further research in this field, but it is obvious that a comprehensive requirements analysis and a general specification framework are still missing. This paper shall provide an adequate answer.

With a similar willingness to close this gap, Pearson et al. (2019) derive requirements and challenges for the use of a blockchain technology in traceability systems in the food industry. The specification framework presented in the following supplements these generally made assumptions with a detailed survey of requirements raised by all stakeholders along supply chains. Therefore, it creates a clearer picture of requirements and challenges, which can be expected in real-world applications of the blockchain technology, as a basis for future research and implementations.

\section{Methodology}

\subsection{Development of the underlying supply chain process model}

The analysis of the requirements addresses a general, industry-independent BBTS. Therefore, a generic mapping of all production and logistics processes is desired. To answer the research question raised and to be able to collect the requirements for the blockchain platform in a structured way, a reference model for the design of supply chains is proposed in the following. The SCPM is built modularly to guarantee standardization and broad applicability, regardless of the length, width and internationality of the supply chain or the product group and product complexity. This makes the research results usable for every company and ensures that development costs and investment risk are kept to a minimum.

Existing models for the description of processes in supply chains do not meet the requirements to be used as a SCPM from a traceability perspective:

The Supply Chain Operations Reference Model (SCOR model), is an industry-independent process model which serves to describe internal and external supply chains. It aims at providing standardized terminology for the description of supply chains. (Stadtler et al. 2015, p. 33; Supply Chain Council 2012, p. 1) However, the presentation of information flows (dealing with the data requirements of participants in a supply chain) is not presented in sufficient detail.

The Value Chain model by Porter is a basic model for the process-oriented description and explanation of value chains. According to Porter, every company is "an accumulation of activities through which its product is designed, manufactured, distributed, delivered and supported". (Porter 1985) The value chain model lacks the necessary object reference to IT systems.

The Aachener production planning and control model (PPS model) is a generally valid process model with the focus on production planning and control. The PPS is regarded from the four different points of view tasks, process architectures, processes and functions. (Schuh et al. 2008, p. 250) The Dortmund Process Chain Model is a process model for process organization in supply chains. It was developed as a concept to address the increasing complexity in the economy since the end of the 20th century. (Clausen 2010, p. 11) Both models, with their strong orientation towards PPS, are not flexible and universal enough for the width of food supply chains. 
The "Architecture of Integrated Information Systems method" (ARIS method) serves as a methodological basis for holistic enterprise modelling and offers a uniform framework for development and modeling methods. The background is the increasing variety of methods for mapping holistic business processes at the end of the 20th century. (Software AG 2016, p. 2) However, the ARIS method does not provide a fitting focus for the requirements of a process model in food supply chains, as it is primarily considering information processes and IT.

Therefore, in this research work an integrated model is developed, which is sufficiently accurate for real processes of food production, logistics and traceability-relevant hygiene to be described. In addition, it is described in sufficient detail to derive and assign corresponding generalizable data requirements for traceability.

Throughout the entire creation process, the SCPM was validated in various ways: 1) with practical experiences (cold chains), 2) on the basis of customer projects, 3) by supplementing the IT-side link to top management systems, and 4) on the basis of pilot process models of two products of the confectionery industry (fine bakery products, chocolate products).

The SCPM is constructed by a beneficial combination of the bottom-up and the top-down approach, namely the countercurrent method. (SOLYP 2016) Starting consideration on the lowest hierarchical level with continuously increasing the degree of aggregation assures to take every single process into account. Thus, the bottom-up perspective facilitates the transferability of the model to real systems, which can be named as a significant strength of the methodology. In contrast, the top-down perspective, a retrograde approach, supports quick model creation with a reasonable degree of abstraction. With regard to the proposed SCPM these advantages take effect as follows: First, the topdown specification of three levels of the model and a roughly determined data basis serve as a modeling framework. This is followed by the bottom-up feedback, in which the processes for segments of the supply chain are recorded and then linked, starting from the third level of activities.

\subsection{Determination and structuring of requirements}

The first step to collect the data requirements is to define and classify the requirements. In this paper, requirements are divided as follows:

- Usage requirements are focused on applicability and contain generally formulated user needs without software-specific features. They answer the question "What must the solution be capable of?" (Hunkirchen et al. 2015)

- Technical requirements include all challenges for the traceability solution that deal with the question "How should the solution work?". These include non-functional and functional requirements for the usability of the system. (Kalenborn 2014)

- Interoperability requirements include methods and standardization needs for the information and communication structure.

According to Kalenborn (2014), all information can be assigned to three different sources: Stakeholders, documents and existing systems. Table 2 shows an overview of the methods used for requirements elicitation from different sources of information: Relevant stakeholders are persons or organizations that are affected by the system and can provide input for its functional development and acceptance. With the help of a systematic literature research and discussion, the different roles and 
interests of institutions in the overall system of food production, transport, sales and consumption are identified. Subsequently, a consolidation of terminology and naming of involved actors along the material flow in the food supply chain as well as third parties with considerable interest was done. Documents include all records, legal texts and standards, which often define the boundary conditions that must be recorded and evaluated before implementation. In addition, important information can be derived from existing systems to avoid errors during the development of the new solution.

Table 2: Methodology of requirements analysis

\begin{tabular}{|c|c|c|c|c|}
\hline Source of information & Methods used & $\begin{array}{c}\text { Usage } \\
\text { requirements }\end{array}$ & $\begin{array}{c}\text { Technical } \\
\text { requirements }\end{array}$ & $\begin{array}{c}\text { Interoperability } \\
\text { requirements }\end{array}$ \\
\hline Stakeholders & $\begin{array}{c}\text { Workshops } \\
\text { Expert interviews }\end{array}$ & $\mathbf{x}$ & $\mathbf{x}$ \\
\hline Documents & Literature research & $\mathbf{x}$ & $\mathbf{x}$ \\
\hline Existing systems & $\begin{array}{c}\text { Literature research } \\
\text { Expert interviews }\end{array}$ & & $\mathbf{x}$ & $\mathbf{x}$ \\
\hline
\end{tabular}

The analysis of the results from literature research, workshops and expert interviews make it possible to determine the usage requirements for the traceability solution. For example, a consumer is interested in whether the product is safe. The analytical core of the requirement from the perspective of the stakeholder, the consumer, is: "What conditions are necessary for the product to be safe from the consumer's perspective?"

For the technical requirements, the results of literature research, workshops and expert interviews are transformed into functional and non-functional user stories and summarized into application-oriented requirements. They contain a short description of the requirement: acceptance criteria describing which conditions the BBTS has to fulfill and other marginal data.

Data collected from the information sources "stakeholders", "documents" and "existing systems" are also systematically analyzed for the interoperability requirements. The analysis aims at an investigation of the systems already in use with regard to data and service interfaces for coupling with a blockchain. The interoperability requirements serve to incorporate all demands for digital frameworks.

When establishing the requirements, it must be ensured that the named aspects are objectively determined, validated and not contradictory. First, the objectivity of a usage requirement is ensured when several stakeholders / persons / sources formulate the same requirement for a specific usage context. Furthermore, the raised requirements must be traceable to the requirements of the context of use. To ensure that the requirements elicitation is done in the most unbiased way, an aspect is only declared as a fundamental requirement if at least two groups of stakeholders demand for it.

Second, the collected requirements must be valid, i.e. the data must be confirmed or, if necessary, corrected by representatives working in this context. In this paper, workshops with different participants of the supply chain were conducted as well as guideline-based interviews. The results can therefore be considered as valid.

Third, a requirement should not directly contradict other existing requirements. Conflicting requirements can occur, e.g. via requirements from different user target groups or in different contexts in which a system is used. If the requirements are contradictory, they are analyzed, discussed and clarified. 


\section{Resulting specification framework}

\subsection{Supply Chain process model}

Any process in a supply chain consists of a sequence of individual steps, which shall be described by a manageable number of general activities. For example, storing fresh fruits is fundamentally different from storing freshly caught fish, but both can be described as storing under specific conditions, in fixed containers and for a defined period of time. In this work almost 40 general steps are identified, which are intended to completely map any supply chain process. Therefore, the developed SCPM serves to create a common basis for the legal (usage) requirements and those of the stakeholders.

Porters value chain model was selected as the structural basis for cross-company tracking, as it offers a holistic and clear view on an entire company or company segment. To add a more detailed perspective, concepts of the SCOR model are transferred, in particular further differentiation of individual activities. Likewise, the concept of supporting processes, which occurs with Porter, was taken up. (Porter 1985; Supply Chain Council 2012) It includes activities that are not part of the primary material flow, but are linked closely enough so that they cannot be neglected with regard to traceability. Furthermore, categories of different activities have been extracted from the literature, such as the categorization of production processes from production theory and the classification of the main components of the transport chain according to DIN 30781-1.

The model consists of three hierarchical levels to represent the material flow, see Figure 4. The lowest, third level contains activities as the smallest building blocks of all processes. Each possible real process step along supply chains in the food industry should be mappable by one of the given activities. The multitude of activities is grouped to form modules. Modules describe subsets of processes that belong to the same business environment, here: inbound logistics, operations, outbound logistics, after-sales service and procurement. Note that modules do not necessarily represent departments.

The combination of all the modules describes a business segment (BS) as part of the second level of the model. Note that all general activities and modules are included in the graphical representation (Figure 4) of every BS even if not all of them might be needed for specific practical applications. By linking all activities of a BS, the value-added stream of a product is depicted.

Finally, different BSs of one company can be interconnected with different BSs of other companies at the first level. With this, the entire value-added network is modelled.

Considering the first level in more detail, there is a total of five modules considered in the SCPM:

- Inbound logistics includes all activities related to the receipt, storage, distribution and transport of incoming resources or products.

- All activities related to the transformation of incoming resources into intermediate or final products, e.g. actual manufacturing activities, are denoted as operations.

- In outbound logistics, all activities related to the collection, storage and physical distribution of products are grouped.

- After-sales service includes all activities that (could) still have an influence on the product after "transfer" to the next BS, or for which data should be stored for traceability purposes.

- The procurement module contains all activities that represent the integration of supporting resources or products. 


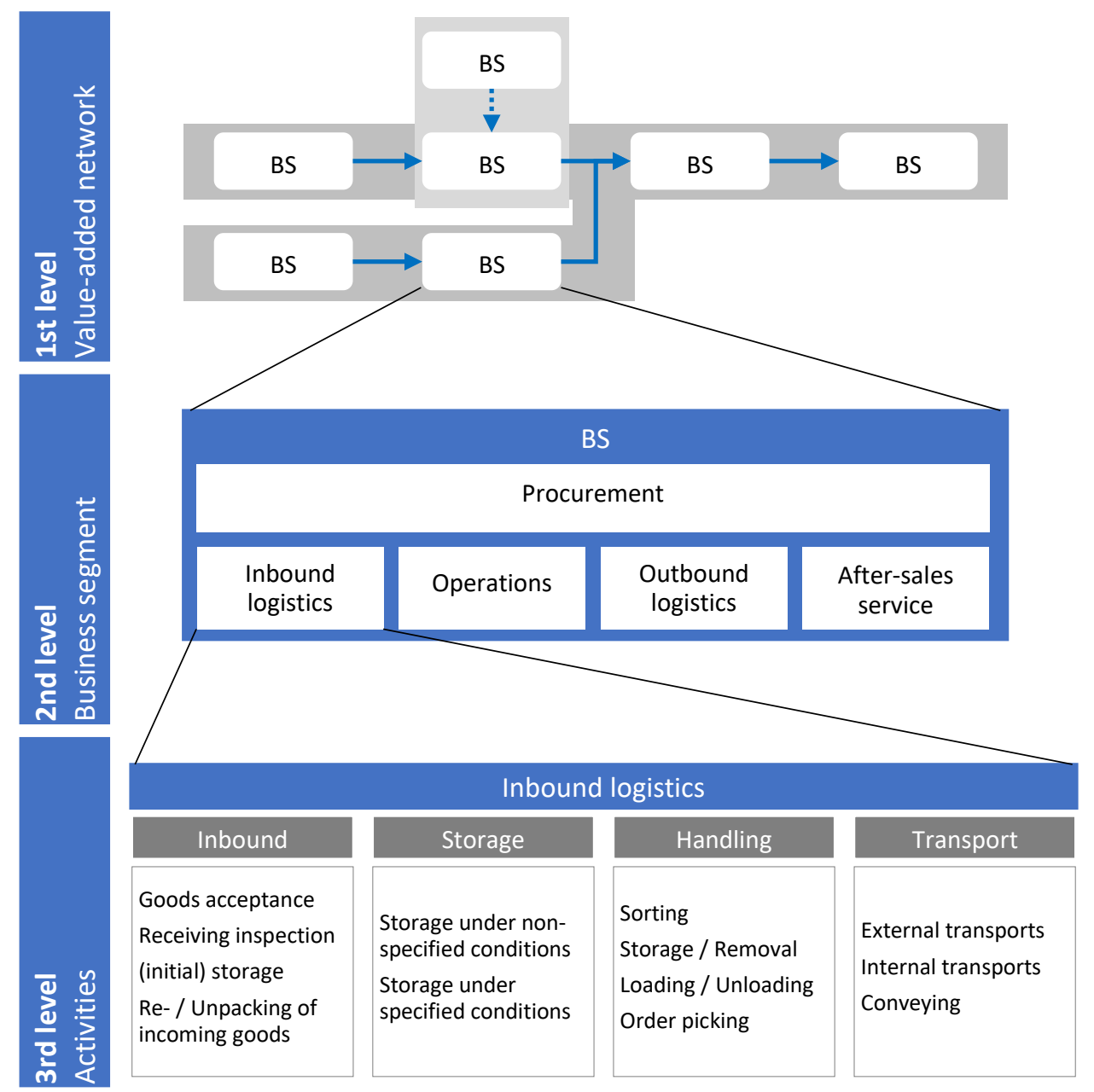

Figure 4: Graphical representation of the SCPM

Procurement differs from the other modules in the type of activities: While other modules follow a chronological ordering, procurement activities may occur at each place of a process. They illustrate exclusively such processes, which merge supporting resources or products into the commodity flow. Each procurement activity implies the inclusion of resources or products, for which, in contrast to primary resources, data must be stored only once or selectively. A raw material can be a primary or supporting resource, depending on the application in the process. This decision must be made individually for each use case. Table 3 shows the overview of all activities assigned to their respective modules.

In addition, the division of BS and activities into primary and supporting value-added relationships, which is based on Porter's value chain, is of crucial importance for the development of the model. (Porter 1985) With the help of this differentiation, elements that are absolutely necessary for tracing - primary - and those that are more subordinate - support - can be marked. Primary value-added relationships exist wherever essential material flows of the main manufacturing process take place and where the company segment changes. Among other things, preliminary and intermediate products as well as resources used are to be recorded here to assure a meaningful traceability of the final product. As an example, the traceability of yogurt should also include information on the milk, since it is identified as a potential source of contamination. Supporting value-added relationships exist wherever means of production, which may have a significant impact on the risk profile of the product, but do not have to be traced themselves, change. 
Table 3: Representation of activities

\begin{tabular}{|c|c|c|c|c|c|c|c|}
\hline & Arrival & \multicolumn{2}{|l|}{ Storage } & \multicolumn{3}{|c|}{ Handling } & Transport \\
\hline 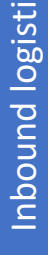 & $\begin{array}{l}\text { - Goods acceptance } \\
\text { - Receiving inspection } \\
\text { - (Initial) storage } \\
\text { - Re- / unpacking of } \\
\text { incoming goods }\end{array}$ & \multicolumn{2}{|c|}{$\begin{array}{l}\text { - Storage under non- } \\
\text { specified conditions } \\
\text { - Storage under specified } \\
\text { conditions }\end{array}$} & \multicolumn{3}{|c|}{$\begin{array}{l}\text { - Sorting } \\
\text { - Storage / removal } \\
\text { - Loading / unloading } \\
\text { - Order picking }\end{array}$} & $\begin{array}{l}\text { - External transports } \\
\text { - Internal transports } \\
\text { - Conveying }\end{array}$ \\
\hline & \multicolumn{2}{|c|}{$\begin{array}{l}\text { Converging } \\
(m \text { units } \rightarrow 1 \text { unit, } m>1 \text { ) }\end{array}$} & \multicolumn{3}{|c|}{$\begin{array}{l}\text { Diverging } \\
(1 \text { unit } \rightarrow n \text { units, } n>1)\end{array}$} & \multicolumn{2}{|c|}{$\begin{array}{l}\text { Linear } \\
(m \rightarrow n \text { with } n, m \in\{0 ; 1\})\end{array}$} \\
\hline $\begin{array}{l}\frac{n}{c} \\
\frac{0}{+0} \\
\frac{\pi}{0} \\
\frac{2}{0} \\
0\end{array}$ & \multicolumn{2}{|c|}{$\begin{array}{l}\text { - Aggregating } \\
\text { - Blending / mixing } \\
\text { - Transformation of one input } \\
\text { into one output while using } \\
\text { other inputs } \\
\text { - Production of one output from } \\
\text { more than one input }\end{array}$} & \multicolumn{3}{|c|}{$\begin{array}{l}\text { - De-Aggregating } \\
\text { - Splitting an input into its } \\
\text { components } \\
\text { - Processing one input into } \\
\text { more than one different } \\
\text { output }\end{array}$} & \multicolumn{2}{|c|}{$\begin{array}{l}\text { - Change of a product (e.g. change } \\
\text { of its position or state) without } \\
\text { the help of other products } \\
\text { - Initial creation of a product (no } \\
\text { upstream nodes) }\end{array}$} \\
\hline \multirow{2}{*}{ 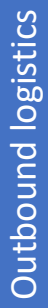 } & \multicolumn{2}{|l|}{ Collecting } & Storage & landling & & nsport & Distribution \\
\hline & \multicolumn{2}{|c|}{$\begin{array}{l}\text { - Quality control } \\
\text { - Preparation for removal / } \\
\text { conveying }\end{array}$} & \multicolumn{4}{|c|}{ - See above (inbound logistics) } & $\begin{array}{l}\text { - Business-to-consumer } \\
\text { - Business-to-business }\end{array}$ \\
\hline \multirow{2}{*}{ 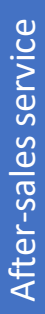 } & Installation \& Repairs & \multicolumn{5}{|c|}{ Training, instructions, manuals } & Product adaptations \\
\hline & $\begin{array}{l}\text { - Installations } \\
\text { - Repairs }\end{array}$ & \multicolumn{5}{|c|}{$\begin{array}{l}\text { - To conduct trainings } \\
\text { - To issue instructions } \\
\text { - To provide manuals }\end{array}$} & $\begin{array}{l}\text { - Subsequent changes to } \\
\text { the product }\end{array}$ \\
\hline$\stackrel{t}{\mathrm{C}}$ & \multicolumn{3}{|l|}{ (Material) equipment } & \multicolumn{4}{|c|}{ Auxiliary / operating \& raw materials } \\
\hline $\begin{array}{l}\frac{\varepsilon}{d} \\
\frac{1}{2} \\
\frac{0}{0} \\
\frac{0}{2}\end{array}$ & \multicolumn{3}{|c|}{$\begin{array}{l}\text { - Procurement of machines } \\
\text { - Procurement of tools } \\
\text { - Procurement of (transport) vehicles }\end{array}$} & \multicolumn{4}{|c|}{$\begin{array}{l}\text { - Procurement of auxiliary materials } \\
\text { - Procurement of operating materials } \\
\text { - Procurement of raw materials }\end{array}$} \\
\hline
\end{tabular}

Examples of such relationships are:

- The characteristics of a machine may affect the product quality of foodstuff. However, the machine itself does not need to be traceable.

- A fertilizer used has an impact on the risks associated with raw materials, but to assure the traceability of a final good it does not need to be traceable itself due to its marginal importance.

Figure 5 schematically shows how such a combination of primary and supporting relationships may look like at the first level of the model. 


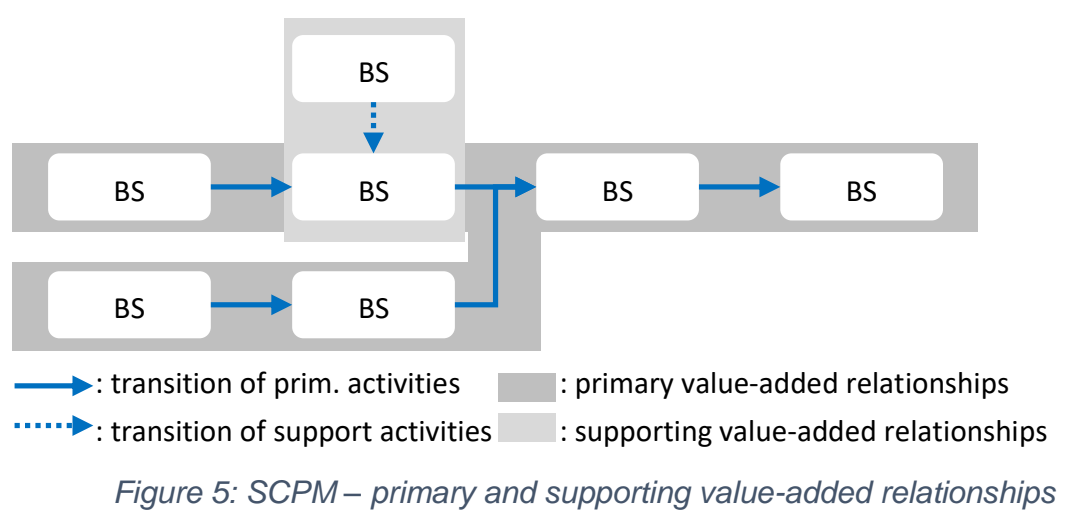

Taking all these components and their hierarchical structure together, the SCPM is built. It will constitute the basis of all explanations and discussions given in the next sections. Especially when it comes to information requirements, it is important to keep in mind that all requested data needs to be provided for all processes modeled here.

\subsection{Usage requirements}

In addition to the material flow, a flow of information relevant for tracing food along supply chains must be established. Therefore, usage requirements related to the activities of the SCPM raised by all stakeholders and by law must be identified. As a central result of this work, a comprehensive overview of such requirements is developed while defining necessary data.

Given legal requirements form the framework for the entire requirements analysis. They involve different stakeholders and can be mapped onto the processes in the SCPM. A general requirement, which is presupposed in many legal texts, such as (basic regulation (EC) No. 178/2002, food hygiene regulation (EC) No. 852/2004, IFS standards, BRC standard, SQF standard etc.), is the existence of a traceability system: A traceability system must be in place to identify the flow of goods across all production, processing and distribution stages. The aim of this system is to relate a product batch to its raw materials, packaging materials, processing and delivery actions. It is important to keep sufficient documentation of all incoming goods, processing and distribution processes.

Derived from the SCPM and further literature review, the following stakeholders have been identified as relevant for data completeness: Suppliers, producers, wholesale / retail, logistics service providers, end consumer as well as food authorities and other third-party institutions.

Through a broad analysis of these stakeholders as data input and output actors and of the relevance of data for traceability, consistency and an appropriate digital SCPM mapping, 58 relevant data classes have been identified. Table 4 shows these data classes divided into six categories. All requirements concerning packaging in supply chains are summarized as packaging data. This includes nutritional labelling and storage instructions, for example. Transport and delivery data aggregate all data classes regarding transport and delivery of goods as well as their identification (shipper / receiver, temperature data, transport labels, etc.) This data must be adequately documented and passed on to the downstream process chain. All data that must be provided by the company independent of the product is assigned to company data. This may include the address of the company and results of company's internal quality inspections, among other things. Usage requirements of operational events (e.g. type of process, records of in-process controls) are summarized in process data. Product-specific 
requirements (batch numbers, quantity specifications) are grouped into product data. All requirements that serve to describe quality are aggregated to Qualities \& Grades.

Table 4: Presentation of usage requirements divided into six data class categories

\begin{tabular}{|c|c|}
\hline Product data & Process data \\
\hline $\begin{array}{l}\text { - Product (name) } \\
\text { - Quantities of the ingredients used } \\
\text { - Internal and external batch number(s) } \\
\text { - Best before date / Expiry date } \\
\text { - Raw materials used } \\
\text { - Product temperature } \\
\text { - Results of quality controls (internal) } \\
\text { - Information on returned goods } \\
\text { - Origin / Country of origin / Location }\end{array}$ & $\begin{array}{l}\text { - Process type } \\
\text { - Location of the process step } \\
\text { - Process date / Time } \\
\text { - Use of animal feed } \\
\text { - Use of biocides and pesticides } \\
\text { - Data for measuring device monitoring } \\
\text { - Recording of in-process controls and } \\
\text { - } \text { results }\end{array}$ \\
\hline Company data & Transport \& Delivery data \\
\hline $\begin{array}{l}\text { - Process owner / Company } \\
\text { - Company address } \\
\text { - Company registration number } \\
\text { - Origin / Country of origin / Location } \\
\text { - Stock register } \\
\text { - Internal company hygiene regulations } \\
\text { - Results of internal and external company } \\
\text { controls }\end{array}$ & $\begin{array}{l}\text { - Load carrier temperature } \\
\text { - Cargo location temperature } \\
\text { - Shipping / Transfer date (delivery date) } \\
\text { - Shipping object / Product } \\
\text { - Location of the goods (truck, warehouse, } \\
\text { - plant) } \\
\text { - Place of departure } \\
\text { - Departure time }\end{array}$ \\
\hline $\begin{array}{l}\text { Qualities \& Grades } \\
\text { - Certificates } \\
\text { - Label (organic / conventional labelling) } \\
\text { - Labelling of GMO goods }\end{array}$ & $\begin{array}{l}\text { - Transport unit / Means of transport } \\
\text { - Transport packaging } \\
\text { - Transport marking: } \\
\text { o Storage / Stacking ability }\end{array}$ \\
\hline Packaging data & Marking: Fragile \\
\hline $\begin{array}{l}\text { - Nutrition labelling } \\
\text { - Big } 7 \text { (calorific value, fat, saturated fatty } \\
\text { acids, carbohydrates, sugar, protein, salt) } \\
\text { - Vitamins / Minerals } \\
\text { - Instruction for use } \\
\text { - Allergen labelling } \\
\text { - Storage advice } \\
\text { - Preservation and use of packaging } \\
\text { - Materials } \\
\text { - } \text { Other information on the goods }\end{array}$ & $\begin{array}{l}\text { Labelling: Cooling requirements } \\
\text { Other warehouse / Transportation } \\
\text { marking } \\
\text { - Transport loads: } \\
\text { O Static, mechanical (stack dipping } \\
\text { pressure) } \\
\text { Dynamic mechanical (vibrations, } \\
\text { shocks) } \\
\text { C Climatic (humidity, temperature) } \\
\text { - Biotic (pest infestation, germ } \\
\quad \text { contamination) } \\
\text { - Consignor / Consignee } \\
\text { - Carrier } \\
\text { - Supplier information } \\
\text { - Manufacturer information } \\
\text { - Packer information }\end{array}$ \\
\hline
\end{tabular}

Table 5 shows the categorized and totaled usage requirements of the stakeholders in their roles as input and output actors. Overall, the requirements are evenly distributed along the supply chain. Data input occurs only among the direct participants of the supply chain. End consumers and Food authorities act exclusively as output actors. 
Table 5: Overview of the number of usage requirements raised per stakeholder

\begin{tabular}{|c|c|c|c|c|c|c|c|c|}
\hline \multirow{6}{*}{ 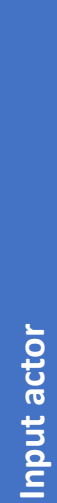 } & & 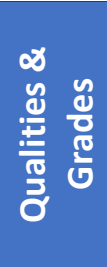 & 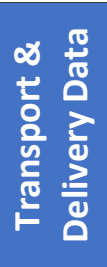 & 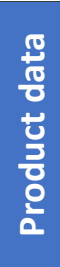 & 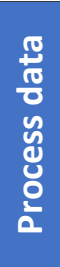 & 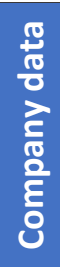 & 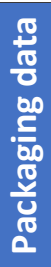 & $\begin{array}{l}\overline{8} \\
\text { o }\end{array}$ \\
\hline & Supplier & 3 & 14 & 8 & 8 & 7 & 8 & 48 \\
\hline & Producer & 3 & 14 & 9 & 8 & 7 & 8 & 49 \\
\hline & Wholesale / retail trade & - & 17 & 4 & 5 & 4 & - & 30 \\
\hline & Logistics service provider & - & 19 & 4 & 4 & 4 & - & 31 \\
\hline & End consumer & - & - & - & - & - & - & 0 \\
\hline \multirow{7}{*}{ 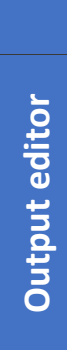 } & Food authority & - & - & - & - & - & - & 0 \\
\hline & Supplier & 3 & 2 & 6 & 4 & 3 & 1 & 19 \\
\hline & Producer & 3 & 20 & 8 & 4 & 3 & 2 & 40 \\
\hline & Wholesale / retail trade & 2 & 22 & 8 & 2 & 3 & 3 & 40 \\
\hline & Logistics service provider & 2 & 23 & 8 & 1 & 3 & 2 & 39 \\
\hline & End consumer & 3 & - & 6 & - & 2 & 8 & 19 \\
\hline & Food authority & 2 & 2 & 8 & 2 & 7 & - & 21 \\
\hline
\end{tabular}

The direct participants of the supply chain (supplier, producer, wholesale/retail, logistics service provider) are primarily interested in transport and delivery data, since it ensures trouble-free communication in regular business and in case of a breakdown. This observation matches the theoretical findings on the importance of linkages between processes running at different locations and in different companies. Product and packaging data are particularly important to the end consumer, since important statements can be derived (shelf life, adherence to the cold chain, origin of raw materials, etc.). This supports the initial motivation of research in BBTS. In addition, food authorities at local and national level are mainly interested in product and company data. In case of a food safety issue, for example, it is of crucial importance for the authorities to get to know all involved partners, the upstream and downstream material flow of the raw materials used, as well as the batch numbers and quantity proportions.

Overall, the presented data classes involve a variety of information, which are of divergent relevance for the stakeholders. Since pure traceability represents the key feature of the BBTS, from which all stakeholders benefit especially in case of food safety issues, data relevant to trace (upstream) and track (downstream) products and their raw materials will play a special role in the remainder of this analysis. This traceability data is to be differentiated from data classes providing additional information on products or processes.

Next to the data requirements, the willingness to share data is a decisive point for the development of a BBTS. End consumers and food authorities as exclusive output actors can be excluded from this analysis. The two largest input actors are suppliers and producers. A literature research and expert interviews with various industrial partners have shown that there is a very heterogeneous opinion on which data would be shared with whom in the supply chain. This creates a need for the possibility of individually adaptive information sharing in the digital system and a strong interrelation of the identified usage requirements with the technical requirements described the next section. 


\subsection{Technical requirements}

A compilation of 19 significant application-oriented aspects is created by analyzing the recorded functional and non-functional requirements of all stakeholders. These technical requirements are divided into five categories as follows:

\section{Access requirements}

- Access to information for everyone: Transmitted traceability data and, if available, further information on a product should always be accessible by everyone, especially by the consumer (e.g. via a website) and by other participants (e.g. via a software).

- Dynamically adaptable access to submitted data for other participants: Access to information beyond traceability data should be generally limitable and dynamically activatable (e.g. food safety event) for different stakeholders according to individual permissions and data shares set by the input actors.

- Access to specific information for food authorities: From their point of view, in case of a control or food safety issue, specific information regarding the source and the buyer of a product should be accessible.

- Visual representation of data: It should be possible to visualize the data so that complex supply chain information can be easily read by any user. For example, a supply chain of a specific product is depicted as a graph for the end consumer.

\section{Data storage requirements}

- High availability: The storage service should be highly available so as not to block other information systems and processes.

- Retrieval of non-product-specific information: It should be possible to share participantrelated information as well as information on assets used by the participant in manufacturing process, including supporting activities. (cleaning, maintenance, repair of a machine etc.).

- Handling of measured values and sensor data: It should be possible to record measured values and sensor data (e.g. temperature data), both manually and automatically.

- Authenticity of data: It should be possible to efficiently prove the authenticity of information to ensure forgery protection, even for large data sets or high-frequency data.

\section{Data processing requirements}

- Extensive evaluation options: There should be extensive evaluation options (for product batches, events, etc.) for the participants of the supply chain, for instance, a product search function to be able to evaluate batches of a certain company for a certain time period.

- Visual representation of measured data trends: The temporal course of measured values should be visually displayed. The representation of target and tolerance values is also desirable to indicate critical deviations.

\section{Notification requirements}

- Active notification of supply chain participants: As soon as events occur, potentially negatively affected supply chain participants should be actively notified so that they can either act themselves or anticipate future supply bottlenecks. 
- Issue of (product-specific) warnings: In case of extraordinary events, such as the discovery of spoiled food, it should be possible to issue warnings to participants, end consumers and legal institutions that are linked to a specific product.

- Monitoring of objects and activities: It should be possible to monitor products and activities, detect the status of a product (location, timestamp, temperature etc.) and save it. The user will be notified when a certain state of an object (e.g., critical temperature) occurs and when a certain activity takes place.

\section{Process mapping requirements}

- Assignments to higher-level units: Traceability should be eased and facilitated by assigning products to higher-level units such as pallets.

- Passing on the responsibility / accountability for a product or object: It should be obvious who is currently responsible for an object or who was responsible for an object at a respective time.

- Creating or removing objects: It should be possible to register new resources and new localities of companies. In addition, it should be possible to remove products or objects so that their further use is no longer valid.

- Food controls: It should be possible to report and view food control results.

- Role and rights management: It should be possible to define different roles and rights for participants of the supply chain, consumers and legal institutions. Not every participant in the supply chain needs or requires the same rights (e.g., reading and writing rights).

- Filing of documents: It should be possible to store, view and share documents such as certificates.

\subsection{Interoperability requirements}

Interoperability requirements include the conditions for managing production and logistics processes in an information system. Especially regarding the acceptance of the BBTS among all stakeholders and the cost-effectiveness, these aspects are significant. There are necessities towards communication structures, common identifiers of products and companies, and other enabling methods for the case of disruptive events (internet failure, missing identifiers on products, etc.) involved. To determine the relevant key issues, the stakeholder-based requirements are evaluated and transferred towards an information system. Thereby, the technical implementation and requirements from the data provider and the user perspective are considered. Consequently, two main categories of interoperability requirements are determined.

\section{Digital communication}

- Interfaces must always be precisely and explicitly defined. Retrievable information should be directly interpretable without extra queries. Considered as a negative example existing identifier with 7 or 8-digit prefixes, where the prefix identifies the company and the following digits identify the product. When retrieving a data set containing such an identifier, the user system needs to further ask the data source about how many digits belong to the prefix to separate the information. This should be avoided by explicit formatting. 
- It must be possible to provide data as batch actions. This supports data completeness and user comfort. Consider as examples, employees in the warehouse who do not need to enter data manually every time but can enter it as a batch once an hour.

- Data must be easily readable by human users. To enhance the user experience, the interaction between stakeholders and the BBTS should be based on graphical interfaces, which depict the supply chain data.

\section{Continuous operation assurance}

- Data should be both retrievable in real time and downloadable in bulk to make it available at process sites without internet or to accelerate local information lookup times in time-sensitive tasks.

- Information can either be transmitted in real time or cached locally and transferred later. Information from process locations with limited connectivity for instance can be provided in a batch transmission periodically.

- It should always be possible to provide and store data on activities in non-chronological order, especially independent on whether predecessor activities have already been reported. As an example, a producer or retailer must be able to report the acceptance of goods to the platform even if the logistics provider submits the transport data only in the evening.

- If the exact identification of a product is not possible for a participant (e.g., due to missing tags on the packaging), it should still be possible to make a partially manual dummy entry to increase data completeness.

- Corrections and subsequent additions in activity data should be possible to improve data completeness and validity.

\section{On the potential of the blockchain technology to meet stakeholder requirements}

This chapter addresses the questions to which extend the blockchain technology is capable of satisfying the requirements given in the specification framework and which challenges arise thereby. For this purpose, general requirements on traceability software systems are derived and summarized in guidelines. Consequently, the potential of blockchain technology to follow these guidelines is assessed. The analysis of usage requirements shows that a traceability software must be able to handle different data classes and types (numbers, text, etc.). In addition, the system must clearly represent the material flow of an entire supply chain and the willingness to share information is an important aspect. From the technical requirements perspective, a traceability software must offer options for individual and dynamic data access limitations. Data processing, data storage, notifications and correctness in process mapping must be taken into account. Considering the interoperability requirements, unique and explicit formatting and the assurance of permanent operability are the main building blocks for the development of traceability software.

The following guidelines are derived:

1. Distinction: Different types of data are generated along supply chains: public, traceabilityrelevant data (product name, batch no. etc.) and sensitive, additional data (temperature data, 
proportions of ingredients, hygiene data etc.). The separation of these data types must be possible in the BBTS.

2. Visibility: Not all data should be visible to every participant every time. Therefore, there must be a role and rights management that regulates data sharing.

3. Transparency \& Accessibility: Access and readability of public and dedicated information must be guaranteed for all stakeholders (supply chain participants, authorities, consumers). The solution should be open to all participants in each supply chain on a non-discriminatory basis.

4. Authenticity, Auditability \& Forgery protection: It must be possible to prove authenticity of information and thus, to ensure protection against forgery. Authenticity must be efficiently verifiable for easily manageable data as well as for large data sets and high-frequency data.

5. Standards: A uniform data transmission framework is required for all participants in the traceability solution, for example, applying the standards of GS1. (GS1 2016)

Considering these guidelines, it can be stated that the blockchain technology offers great potential to form the basis of a traceability software solution. In the following, it will be examined in detail why this innovative technology is suitable for the described application, and for which technical and economic challenges of the current time it can offer solutions.

In the sense of guidelines 3 and 4 , the blockchain configuration public permissioned with $a$ performance-preserving byzantine fault tolerance consensus algorithm is suggested as a promising basis for a BBTS in food supply. The blockchain will be freely accessible and the content is publicly readable (guideline 3 ), but content and configuration can only be modified by selected actors. Even if public data access contradicts guideline 2 at the first sight, this form should be chosen to provide a transparent information system and to assure the fundamental trust of all stakeholders.

To perfectly meet the requirements given in the specification framework and follow the guidelines 1 , 2 and 3 simultaneously, further attention needs to be paid to the distinction between public, traceability-relevant and sensitive, additional data. For access to sensitive information to remain in control of the data owner, a collaboration between decentralized blockchain services and data provisioning services is suggested, see Figure 6 . While public data is stored in the blockchain network (marked in blue), data sensitive to the participants is stored in external services owned or at least controlled by the data-providing actor (marked in green). To facilitate restricted data access and forgery protection at the same time, checksums of the data sets are regularly written to the public permissioned BBTS through the applications and services marked in yellow. Thus, every participant can validate the originality of the data at any time, participants with reading rights set by the input actor can access the data at any time and, in case of a food crisis, relevant information can be shared fast and bilaterally with legal authorities.

Food hygiene data can be considered as an example. The requirements elicitation has shown that this data is classified as sensitive by many companies. This data can be stored in data provisioning services and shared if necessary. Additionally, any data with a given right for erasure must be stored in data provisioning services. Even if the blockchain offers encryption features to limit the visibility of information, it is not erasable. Furthermore, it is not recommended to store high-frequency data in a blockchain. A special case related to food supply is constituted, for instance, by temperature data, as it is likely to exceed the storage capacity of a blockchain network and, thus, can only be stored suitably aggregated as public data. It is proposed to develop a suitable checksum method for high-frequency 
data that stores a checksum over a batch of data in the blockchain only after a threshold of volume or time is reached. This idea perfectly matches the two-part architecture of the BBTS suggested above.

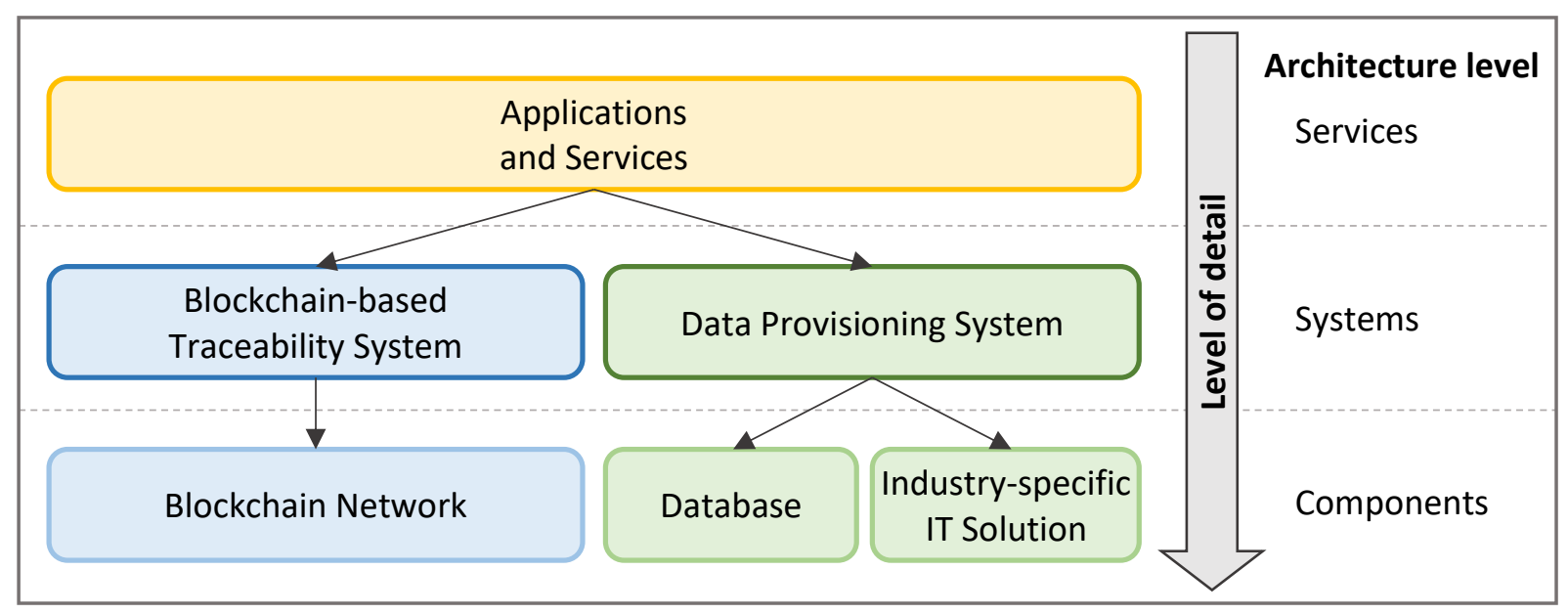

Figure 6: Service-oriented BBTS architecture

The requirements of authenticity and auditability (guideline 4) are native concepts in blockchain technology (chapter 2.2). It is suggested that the private key used to sign transactions should only be present on the participant's local computer, so that no access data can be stolen even by compromising a publicly accessible blockchain service. The concept of client-side private keys enables further advantages in the accessibility (guideline 3 ) for write-authorized participants. It is possible to allow service providers to take over the operation of the blockchain nodes, but server administrators cannot influence the content of the blockchain without access to the private key. It is also proposed that multiple supply chain participants jointly operate a node to save costs.

When a blockchain is operated by a consortium as in the public permissioned case, a contractual set of governance rules are required. It is suggested that these rules ensure the independence of the individual members, a non-discriminatory joining process and the transparency of the development and decision-making processes of the BBTS, so that organizational co-determination, transparency and auditability are also provided (guideline 3 and 4 ).

Regarding a public permissioned BBTS, every user with technical expertise can run its own blockchain node, connect to the network using native technology, and obtain a full copy of the data. To improve the accessibility and readability of the information shared for all users (guideline 3 ), the development of software applications with graphical user interfaces, potentially web-based, is suggested (see marked in yellow in Figure 6). Since the elicitation of usage requirements highlights different needs and motivations of stakeholders, a beneficial application infrastructure may provide a desktop software connected to the BBTS for supply chain participants and legal authorities together with an easily accessible website for end consumers. Thereby, the distinction between unlimited access to public, traceability-relevant information for the end consumer and limited, role-based access to additionally provided, sensitive data for participants and authorities can be realized.

The requirement for uniform standards for the transmission of data (guideline 5) is a mandatory prerequisite for the use of blockchain, as the interpretation and validation of information requires welldefined data structures. This can be solved, for example, using the standards of GS1, which are specifically created for processes in production and logistics. Considering the food industry and safety 
issue, the standard must be extended by several data structures that cannot be mapped by now. Among others, standards for the report of quality controls, temperature measuring and mandatory food-specific information like the catch area for fish are not yet present. However, since the GS1 standard is easily extendable, future research and developments will be able to close this gap. (GS1 2016)

Overall, it can be stated that the blockchain technology shows great potential in meeting all the requirements summarized in the developed guidelines.

In addition to satisfy the guidelines, there are economic challenges with regard to acceptance and costeffectiveness that blockchain can help to address. As described in the introduction, there are still cases where information exchange does not take place, even if supply chains have the necessary IT capability and trust among partners. This could be due to lack of information accuracy and the remaining fear of information leakage. Blockchain technology offers possible solutions for these challenges.

\section{Conclusions}

In this paper, a specification framework is developed by deeply analyzing the requirements for a BBTS that enables its users to improve the transparency and security of food supply. It consists of a supply chain process model, which describes all activities relevant for food traceability, a collection of usage requirements formulated as relevant data classes, a summary of technical requirements regarding data access, storage and processing, notifications and process mapping, and two categories of interoperability requirements necessary to assure digital communication and permanent operability of the BBTS.

In the collection and analysis of the requirements, a wide range of views of the relevant stakeholders, namely the participants of the supply chain, end consumers and legal authorities, are taken into account. Data availability, accuracy and the willingness to share constitute key aspects of the identified needs and worries. This results in the necessity of individual and dynamic data access limitations and a sophisticated roles and rights management as a central requirement of a BBTS. Additionally, a general model to represent various types of processes in a unified but sufficiently detailed manner appears to be of significant importance, since information need to be interpreted and transferred throughout the whole supply chain.

From the specification framework, six guidelines any traceability software solution needs to satisfy are derived. Subsequently, the applicability of blockchain technology is positively evaluated.

To apply a blockchain network in a traceability solution for the food industry, a two-part architecture using a public permissioned blockchain with a performance-preserving byzantine fault tolerance consensus algorithm is most promising. A distinction between public, traceability-relevant data and sensitive, additional data is necessary to assure fast food tracing in case of a crisis, on the one hand, and sufficient access control and trust of data-providing companies, on the other hand. This can be realized by the two-part architecture, where traceability-relevant information and checksums of external data are stored with public access and sensitive, additional information are held in data provisioning services owned and controlled by input actors.

The proposed specification framework shows a wide range of potential usages in related research. The recorded interoperability requirements may be detailed to a precise description of IT interfaces for a 
BBTS. In addition, the developed supply chain process model provides a well-founded basis for any company and research partner when dealing with traceability software. It clearly shows how realworld processes can be mapped onto a digital twin.

Finally, there are several open questions that lead us on to interesting research work in the future. How can existing solutions be validated using this paper's extensive requirements analysis? Are there other innovative IT infrastructures besides the blockchain technology fulfilling the developed guidelines? How can the requirements analysis conducted be applied to the development of IT systems for supply chains of other products (non-food, LFCM, etc.)?

\section{Acknowledgements}

We would like to thank our colleagues in the SiLKe project team for their cooperation during the requirements elicitation. We would also like to thank our colleagues for their valuable comments and feedback on the manuscript.

\section{Funding sources}

This work was funded by the German Federal Ministry of Education and Research on the civile security research program. The results were developed within the research project SiLKe - Safe food chain (https://www.projekt-silke.de/en/). SiLKe represents a provider-neutral and nationwide project. Next to various allied institutions and companies, the main participating partners are FIR e.V. at the RWTH Aachen University, Fraunhofer Institute for Applied Information Technology, fTrace GmbH, FZI Research Center for Information Technology, Hochschule Niederrhein - University of Applied Sciences, PSI Logistics GmbH and Qinum GmbH.

\section{References}

Badia-Melis, R.; Mishra, P.; Ruiz-García, L. (2015): Food traceability: New trends and recent advances. A review. In Food Control 57, pp. 393-401. DOI: 10.1016/j.foodcont.2015.05.005.

Bhatt, T.; Buckley, G.; Hickey, C.; Lothian, P.; McEntire, J. C.; Sterling, B. (2013): Making traceability work across the entire food supply chain. In Journal of food science 78 Suppl 2, B21-7. DOI:

10.1111/1750-3841.12278.

Cao, S.; Dulleck, U.; Warwick, P.; Turner-Morris, C.; Natanelov, V.; Foth, M. (2020): BeefLedger blockchain-credentialed beef exports to China: Early consumer insights. DOI:

10.13140/RG.2.2.23195.28961.

Caro, M. P.; Ali, M. S.; Vecchio, M.; Giaffreda, R. (2018): Blockchain-based Traceability in Agri-Food Supply Chain Management: A Practical Implementation. In loT Vertical an Topical Summit on Agriculture - Tuscany, pp. 1-4. DOI: 10.1109/IOT-TUSCANY.2018.8373021.

Casado-Vara, R.; Prieto, J.; La Prieta, F.; Corchado, J. M. (2018): How blockchain improves the supply chain: case study alimentary supply chain. In Procedia Computer Science 134, pp. 393-398. DOI: 10.1016/j.procs.2018.07.193. 
Casino, F.; Kanakaris, V.; Dasaklis, T. K.; Moschuris, S.; Stachtiaris, S.; Pagoni, M.; Rachaniotis, N. P. (2020): Blockchain-based food supply chain traceability: a case study in the dairy sector. In International Journal of Production Research, pp. 1-13. DOI: 10.1080/00207543.2020.1789238.

Castro, M.; Liskov, B. (2002): Practical byzantine fault tolerance and proactive recovery. In ACM Trans. Comput. Syst. 20 (4), pp. 398-461. DOI: 10.1145/571637.571640.

Clausen, U. (Ed.) (2010): Wege zur innovativen Fabrikorganisation. With assistance of Axel Kuhn. Dortmund: Verl. Praxiswissen (Fabrikorganisation).

Croxson, A.; Sharma, R. S.; Wingreen, S (2019): Making Sense of Blockchain in Food Supply-Chains. In Australasian Conference on Information Systems, pp. 97-107.

Dyckhoff, H.; Spengler, T. S. (2010): Produktionswirtschaft. 3. Auflage. Berlin, Heidelberg: Springer Berlin Heidelberg.

GS1 (2016): EPC Information Services (EPCIS) Standard. Release 1.2. Edited by GS1 AISBL. Available online at https://www.gs1.org/sites/default/files/docs/epc/EPCIS-Standard-1.2-r-2016-09-29.pdf, updated on September 2016.

Hackett, R. (2017): Walmart Explores Blockchain for Delivery Drones. In Fortune, 2017. Available online at https://fortune.com/2017/05/30/walmart-blockchain-drones-patent/, checked on $11 / 29 / 2020$.

Hackius, N.; Petersen, M. (2017): Blockchain in Logistics and Supply Chain: Trick or Treat? In Digitalization in Supply Chain Management and Logistics. DOI: 10.15480/882.1444.

Hunkirchen, P.; Ismer, A.; Ohler, C. (2015): Usability-Modifikation: Leitfaden Nutzungsanforderungen. Edited by Fraunhofer FIT.

Kalenborn, A. (2014): Angebotserstellung und Planung von Internet-Projekten. Die werkzeugbasierte "Modeling by Example"-Methode. Wiesbaden: Springer Fachmedien Wiesbaden.

Kamilaris, A.; Fonts, A.; Prenafeta-Boldú, F. X. (2019): The rise of blockchain technology in agriculture and food supply chains. In Trends in Food Science \& Technology 91 (Mai), pp. 640-652. DOI: 10.1016/j.tifs.2019.07.034.

Lechner, U.; Stocker, F. (2020): NutriSafe Monitor. Resilienz und Blockchain-Technologie in Lebensmittelproduktion und Logistik. $1^{\text {st }} \mathrm{ed}$. München.

Mirabelli, G.; Solina, V. (2020): Blockchain and agricultural supply chains traceability: research trends and future challenges. In Procedia Manufacturing 42, pp. 414-421. DOI:

10.1016/j.promfg.2020.02.054.

Morabito, V. (2017): Business Innovation Through Blockchain. The B ${ }^{3}$ Perspective. Cham: Springer International Publishing.

Nakamoto, S. (2008): Bitcoin: A Peer-to-Peer Electronic Cash System. Available online at https://bitcoin.org/bitcoin.pdf, checked on 11/26/2020.

Ongaro, D.; Ousterhout, J. (2014): In search of an understandable consensus algorithm. In Proceedings of the 2014 USENIX Conference on USENIX Annual Technical Conferences, pp. 305-320. 
Pearson, S.; May, D.; Leontidis, G.; Swainson, M.; Brewer, S.; Bidaut, L. et al. (2019): Are Distributed Ledger Technologies the panacea for food traceability? In Global Food Security 20, pp. 145-149. DOI: 10.1016/j.gfs.2019.02.002.

Pérez Ferreira Chaves, D.; Peter, T. (2018): Der Einsatz von Rückverfolgbarkeitssystemen in der Industrie - Ergebnisse einer Studie. DOI: 10.19211/KUP9783737650519.

Porter, M. E. (1985): Competitive advantage. Creating and sustaining superior performance. New York: Free Press.

Reschke, J. (2019): Sichere Lebensmittelkette durch Anwendung der Blockchain-Technologie (SILKE). Edited by Bundesministerium für Bildung und Forschung.

Salah, K.; Nizamuddin, N.; Jayaraman, R.; Omar, M. (2019): Blockchain-Based Soybean Traceability in Agricultural Supply Chain. In IEEE Access 7, pp. 73295-73305. DOI: 10.1109/ACCESS.2019.2918000.

Schuh, G.; Stich, V.; Schmidt, C. (2008): Produktionsplanung und -steuerung in Logistiknetzwerken. In Peter Nyhuis (Ed.): Beiträge zu einer Theorie der Logistik. Berlin, Heidelberg: Springer Berlin Heidelberg, pp. 249-274.

Schütte, J.; Fridgen, G.; Prinz, W.; Rose, T.; Urbach, N.; Hoeren, T. et al. (2017): Blockchain. Technologien, Forschungsfragen und Anwendungen. Fraunhofer.

Software AG (2016): ARIS-Methode. Version 9.8 - Service Release 3. Darmstadt.

SOLYP (2016): Top-down, Bottom-up oder Gegenstromverfahren. Welche Planungsrichtung passt am besten zu Ihrem Unternehmen? Available online at https://www.solyp.com/de/blog/article/planungsrichtung-gegenstromverfahren.html, checked on 9/29/2019.

Sommer, P. (2007): Umweltfokussiertes Supply Chain Management. Am Beispiel des Lebensmittelsektors. 1. Aufl. Wiesbaden: Deutscher Universitäts-Verlag.

Stadtler, H.; Kilger, C.; Meyr, H. (2015): Supply Chain Management and Advanced Planning. Berlin, Heidelberg: Springer Berlin Heidelberg.

Supply Chain Council (2012): SCOR supply chain operations reference model. Revision 11.0. USA: The Supply Chain Council.

Tian, F. (2017): A supply chain traceability system for food safety based on HACCP, blockchain \& Internet of things. In IEEE Press, pp. 1-6. DOI: 10.1109/ICSSSM.2017.7996119.

Vadgama, N.; Tasca, P. (2020): An Analysis of blockchain adoption in supply chains between 2010 and 2020. In ArXiv abs/2010.00092.

Waskow, F.; Burdick, B. (2020): Kennzeichnung und Glaubwürdigkeit regionaler Lebensmittel. Position und Forderungen der Verbraucherzentrale NRW. Edited by Verbraucherzentrale NRW.

Welzel, C. (2017): Mythos Blockchain: Herausforderung für den öffentlichen Sektor. 1. Auflage. Berlin: Kompetenzzentrum Öffentliche IT, Fraunhofer-Institut für Offene Kommunikationssysteme FOKUS. 
Wüst, K.; Gervais, A. (2018): Do you Need a Blockchain? In : 2018 Crypto Valley Conference on Blockchain Technology. CVCBT 2018 : 20-22 June 2018, Zug, Switzerland : proceedings. With assistance of Emin Gün Sirer, Arthur Gervais, Alexander Denzler. 2018 Crypto Valley Conference on Blockchain Technology (CVCBT). Zug, 6/20/2018 - 6/22/2018. Crypto Valley Conference on Blockchain Technology; Institute of Electrical and Electronics Engineers; IEEE Computer Society; CVCBT.

Piscataway, NJ: IEEE, pp. 45-54.

Zhang, A.; Mankad, A.; Ariyawardana, A. (2020): Establishing confidence in food safety: is traceability a solution in consumers' eyes? In Journal auf Consumer Protecetion and Food Safety. DOI:

10.1007/s00003-020-01277-y.

Zheng, Z.; Xie, S.; Dai, H. N.; Chen, X.; Wang, H. (2018): Blockchain challenges and opportunities: a survey. In IJWGS 14 (4), p. 352. DOI: 10.1504/IJWGS.2018.095647. 